\title{
Simian Immunodeficiency Virus
}

National Cancer Institute

\section{Source}

National Cancer Institute. Simian Immunodeficiency Virus. NCI Thesaurus. Code C14274.

An HIV-like virus that infects monkeys, chimpanzees, and other non-human primates.

(AIDS Info HIV Glossary) 